\title{
$\mathrm{H}$
}

\section{Preclinical Systemic Delivery of Adeno-Associated $\alpha$-Sarcoglycan Gene Transfer for Limb-Girdle Muscular Dystrophy}

\author{
Danielle A. Griffin, ${ }^{1,2}$ Eric R. Pozsgai, ${ }^{1,2}$ Kristin N. Heller, ${ }^{1}$ Rachael A. Potter, ${ }^{1,2}$ \\ Ellyn L. Peterson, ${ }^{1,2}$ and Louise R. Rodino-Klapac ${ }^{2, *}$ \\ ${ }^{1}$ Center for Gene Therapy, The Research Institute at Nationwide Children's Hospital, Columbus, Ohio, USA; ${ }^{2}$ Sarepta Therapeutics, Inc., Cambridge, \\ Massachusetts, USA.
}

Limb-girdle muscular dystrophy type 2D/R3 (LGMD2D/R3) is a progressive muscular dystrophy that manifests with muscle weakness, respiratory abnormalities, and in rare cases cardiomyopathy. LGMD2D/R3 is caused by mutations in the SGCA gene resulting in loss of protein and concomitant loss of some or all components of the dystrophin-associated glycoprotein complex. The sgca-null $\left(\mathrm{sgca}^{-/-}\right)$mouse recapitulates the clinical phenotype of patients with LGMD2D/R3, including dystrophic features such as muscle necrosis and fibrosis, elevated serum creatine kinase (CK), and reduction in the generation of absolute muscle force and locomotor activity. Thus, $\mathrm{sgca}^{-/-}$mice provide a relevant model to test the safety and efficacy of gene transfer. We designed a self-complementary AAVrh74 vector containing a codon-optimized full-length human SGCA (hSGCA) transgene driven by a muscle-specific promoter, shortened muscle creatine kinase (tMCK). In this report, we test the efficacy and safety of scAAVrh74.tMCK.hSGCA in $\mathrm{sgca}^{-1-}$ mice using a doseescalation design to evaluate a single systemic injection of $1.0 \times 10^{12}, 3.0 \times 10^{12}$, and $6.0 \times 10^{12} \mathrm{vg}$ total dose compared with vehicle-treatment and wild-type mice. In $\mathrm{sgca}^{-/}$mice, treatment with scAAVrh74.tMCK.hSGCA resulted in robust expression of $\alpha$-sarcoglycan protein at the sarcolemma membrane in skeletal muscle at all doses tested. In addition, scAAVrh74.tMCK.hSGCA was effective in improving the histopathology of limb and diaphragm muscle of $\mathrm{sgca}^{-/-}$ mice, as indicated by reductions in fibrosis, central nucleation, and normalization of myofiber size. These molecular changes were concomitant with significant increases in specific force generation in the diaphragm and tibialis anterior muscle, protection against eccentric force loss, and reduction in serum CK. Locomotor activity was improved at all doses of vector-treated compared with vehicle-treated $\mathrm{sgca}^{-/-}$mice. Lastly, vector toxicity was not detected in a serum chemistry panel and by gross necropsy. Collectively, these findings provide support for a systemic delivery of scAAVrh74.tMCK.hSGCA in a clinical setting for the treatment of LGMD2D/R3.

Keywords: limb-girdle muscular dystrophy, LGMD, $\alpha$-sarcoglycan, scAAVrh74.tMCK.hSGCA, dose-escalation, gene therapy

\section{INTRODUCTION}

LIMB-GIRDLE MUSCULAR DYSTROPHY (LGMD) is a heterogeneous group of genetic forms of muscular dystrophy with many subtypes that are each caused by a unique mutation and compilation of symptoms. ${ }^{1}$ The sarcoglycanopathies are included as a subset of LGMDs and comprise four major subtypes, namely LGMD2C/R5, -D/R3, -E/R4, and -F/R6, of which each subtype is caused by mutations in the gene that codes for a sarcoglycan protein subunit within the sarcoglycan complex (i.e., $\gamma$-sarcoglycan, $\alpha$-sarcoglycan, $\beta$-sarcoglycan, and $\delta$-sarcoglycan, respectively). ${ }^{1,2}$ Sarcoglycans play a vital role in preventing muscle damage during muscle contraction and all four sarcoglycans must be present to form a functional sarcoglycan complex. ${ }^{1,2}$ The analogous features of the LGMDs are the weakening and atrophy of proximal muscles, specifically in the limb-girdle region. ${ }^{1,2}$ However, even within each of the LGMD subtypes, there is considerable variability in the age of onset, severity, prognosis, and disease progression. ${ }^{1}$

\footnotetext{
*Correspondence: Dr. Louise R. Rodino-Klapac, Sarepta Therapeutics, Inc., 215 First Street, Cambridge, MA 02142, USA. E-mail: Irodinoklapac@sarepta.com
}

(c) Danielle A. Griffin et al. 2021; Published by Mary Ann Liebert, Inc. This Open Access article is distributed under the terms of the Creative Commons Attribution Noncommercial License [CC-BY-NC] (http://creativecommons.org/licenses/by-nc/4.0/) which permits any noncommercial use, distribution, and reproduction in any medium, provided the original author(s) and the source are cited. 
LGMD subtype 2D/R3 (LGMD2D/R3), often referred to as $\alpha$-sarcoglycanopathy, is caused by mutations in the SGCA gene, which leads to complete or reduced loss of functional protein with impairment of other structural components of the dystrophin-associated protein complex. ${ }^{3,4}$ Notably, loss of the $\alpha$-sarcoglycan $(\alpha$-SG) protein leads to a progressive muscular dystrophy with deteriorating muscle function, with onset from 1 to 15 years of age. ${ }^{5}$ Symptoms include the following: delayed ambulation, weakness in proximal muscles caused by fat replacement and fibrosis, elevated creatine kinase (CK), scoliosis, and joint contractures. ${ }^{1,6}$ The debilitating disease often leads to wheelchair dependency and death due to respiratory failure. ${ }^{4,6}$ To date, there are no diseasemodifying therapies for LGMD2D/R3. ${ }^{5,6}$

The $\mathrm{sgca}^{-/}$murine knockout model of LGMD2D/R3 lacks $\alpha$-SG protein and displays a dystrophic phenotype similar to the human disease due to its ongoing and progressive muscle necrosis that occurs with age. ${ }^{7}$ Specifically, the $\mathrm{sgca}^{-/-}$mice display other molecular and chemical characteristics, which include elevated CK, centralized nuclei $(\mathrm{CN})$, increased necrosis, fibrosis, and inflammation. ${ }^{7}$ In addition, the mice recapitulate the human disease with their presentation of functional deficits in muscle force generation and ambulation, thus making the $\mathrm{sgca}^{-/-}$mice an ideal model to study and assess the effects of disease-modifying therapies. ${ }^{7}$

Gene transfer therapy is a promising modality given the monogenetic nature of the disease. ${ }^{5,6} \mathrm{We}$ previously conducted a preclinical comparison study delivering the adeno-associated virus (AAV) vector carrying the fulllength hSGCA cDNA driven by a muscle-specific promoter (shortened muscle creatine kinase, tMCK). ${ }^{8}$ This was packaged into an AAV1 and delivered intramuscularly into the tibialis anterior (TA) compartment of $\mathrm{sgca}^{-/-}$ mice. The results from this previous comparison study confirmed that the tMCK promoter was more efficient in transducing muscle fibers than MCK, cytomegalovirus, or desmin promoters. ${ }^{8}$

To further increase transduction efficiency in muscle fibers, we have packaged the same full-length SGCA, driven by tMCK, into an AAVrh74 vector. The AAVrh74 vector has been used previously in various studies to deliver transgenes successfully, including GALGT2, ${ }^{9}$ dysferlin, ${ }^{10} \beta$-sarcoglycan, ${ }^{11,12}$ and microdystrophin. ${ }^{13}$ More recently, local intravascular delivery of this construct (scAAVrh74.tMCK.hSGCA) promoted robust $\alpha$-SG protein expression (relative to baseline) at the sarcolemma membrane of muscle fibers 180 days postgene transfer in patients with LGMD2D/R3 that was associated with local functional muscle improvement. ${ }^{14}$ Here we use a systemic (intravenous) delivery approach to administer scAAVrh74.tMCK.hSGCA to all muscles through the lateral tail vein of $\mathrm{sgca}^{-/-}$mice to examine safety and efficacy, focusing on functional improve- ment after gene transfer. In this dose-escalation study, we demonstrated the successful systemic gene transfer of scAAVrh74.tMCK.hSGCA as shown by biodistribution of vector genome copies, robust muscle transduction in all skeletal muscles, and functional restoration of the TA.

\section{MATERIALS AND METHODS Animal models}

All procedures were approved by The Research Institute at the Nationwide Children's Hospital Institutional Animal Care and Use Committee. C57BL/6-TgN homozygous mice were provided as gift from Kevin Campbell. ${ }^{7}$ Knockout $\left(\mathrm{sgca}^{-/-}\right)$mice were bred and maintained as homozygous animals under standardized conditions in the Animal Resources Core at the Research Institute at Nationwide Children's Hospital (RINCH). Wild-type (WT) C57/BL6 mice were from the breeding colony at RINCH and purchased from The Jackson Laboratory. Mice were maintained on Teklad Global Rodent Diet (3.8\% fiber, $18.8 \%$ protein, $5 \%$ fat chow) with a $12: 12$-h dark:light cycle. All animals were housed in standard mouse cages with food and water ad libitum. For all experiments, mice from both sexes were used.

\section{Genotyping}

DNA genotyping was used to identify $\mathrm{sgca}^{-/-}$mice. DNA from tail clippings was isolated and analyzed by polymerase chain reaction (PCR) using OneTaq DNA Polymerase (New England Biolabs, Ipswich, MA). A series of primers was used in the PCR analysis to determine the SGCA knockout status. The following primers and conditions were used: Intron1 (CAGGGCTGGGAGC TGGGTTCTG); mutant primer-intron 3 (CCCAGGG CCTTGATGCCT); and NEOTR (GCTATCAGGACAT AGCGTTGGCTA). Reactions were carried out on genomic DNA for 30 cycles under the following conditions: $94^{\circ} \mathrm{C}, 5 \mathrm{~min} ; 94^{\circ} \mathrm{C}, 1 \mathrm{~min} ; 64^{\circ} \mathrm{C}, 1 \mathrm{~min} ; 72^{\circ} \mathrm{C}, 2.5 \mathrm{~min}$; and $72^{\circ} \mathrm{C}, 7 \mathrm{~min}$.

\section{hSGCA gene construction}

The scAAVrh74.tMCK.hSGCA transgene cassette was made using an AAV vector DNA plasmid pAAV.tMCK.hSGCA-neo, by inserting the tMCK expression cassette driving a codon-optimized hSGCA cDNA sequence (human cDNA, GenBank Accession No. U08895) into the self-complementary vector backbone pHpa7. The only viral sequences included in this vector are the inverted terminal repeats (ITRs) of AAV2, which are required for both viral DNA replication and packaging of the rAAV vector genome. One of the ITRs has a targeted deletion of the terminal resolution site to restrict replication from this ITR facilitating generation of the dimeric replicative form for self-complementary vector packaging. The 
AAVrh74 virus has been proven in mice, nonhuman primates, and humans to be safe and highly efficient in transducing muscle across the vascular barrier. ${ }^{9,13-15}$

\section{Vector production}

AAVrh74.tMCK.hSGCA was packaged into the AAV serotype rh74 capsid using the standard triple transfection protocol as previously described. ${ }^{16-18}$ A quantitative PCR (qPCR)-based titration method was used to determine an encapsulated vector genome titer utilizing a Prism 7500 Fast TaqMan detector system (PE Applied Biosystems). ${ }^{19}$

\section{Gene delivery}

Systemic delivery in mice. Systemic delivery was administered via injection of vector into the tail vein of $\mathrm{sgca}^{-/-}$mice. Mice were randomly assigned and injected with $1.0 \times 10^{12} \operatorname{vg}(n=6,3$ male $[\mathrm{M}] / 3$ female $[\mathrm{F}])$, $3.0 \times 10^{12} \mathrm{vg}(n=6,1 \mathrm{M} / 5 \mathrm{~F})$, or $6.0 \times 10^{12} \mathrm{vg}(n=6,3 \mathrm{M} /$ $3 \mathrm{~F})$ total dose $\left(5.0 \times 10^{13}, 1.0 \times 10^{14}\right.$, and $2.0 \times 10^{14} \mathrm{vg} / \mathrm{kg}$, respectively) of scAAVrh74.tMCK.hSGCA diluted in lactated Ringer's solution (vehicle, LR) or LR alone in the untreated cohort $\left(\mathrm{sgca}^{-/-} \mathrm{LR}, n=6,3 \mathrm{M} / 3 \mathrm{~F}\right)$ in a 200 $250 \mu \mathrm{L}$ volume using a 30 -gauge ultrafine insulin syringe. All treated mice were injected at 4-5 weeks of age.

\section{Laser monitoring of open-field cage activity}

An open-field activity chamber was used to determine the overall activity of the experimental mice. Mice at 1617 weeks of age from the WT C57BL/6 $(n=6,6 \mathrm{M})$ and $\mathrm{sgca}^{-/-} \mathrm{LR}(n=6,3 \mathrm{M} / 3 \mathrm{~F})$ control groups, along with scAAVrh74.tMCK.hSGCA 16- to 17-week-old-treated $\mathrm{sgca}^{-/-}$mice ( $n=6$ per dose), were subjected to analysis following a previously described protocol, ${ }^{20,21}$ with several modifications. Cohorts were injected 1 week apart from one another to eliminate variability in endpoint age. Sessions were broken down by cohort. All mice were tested at the same time of day, between the hours of 6:10AM and 8:30AM, when mice are most active. All mice were tested in an isolated room under dim light and with the same handler each time. Also, to reduce anxiety and keep behavioral variables at a minimum that could potentially affect the normal activity of the mice and consequently the results of the assay, we tested mice that were not individually housed. ${ }^{22}$

Mouse activity was monitored using the Photobeam activity system (San Diego Instruments, San Diego, CA). This system uses a grid of invisible infrared light beams that traverse the animal chamber front to back and left to right to monitor the position and movement of the mouse within an $\mathrm{x}-\mathrm{y}-\mathrm{z}$ plane. Activity was recorded for 1 -h cycles at 5-min intervals. Mice were acclimatized to the activity test room for an initial 1-h session 3 and 4 days before data acquisition began. Mice were tested in individual chambers. The testing equipment was cleaned between each use to reduce mouse reactionary behavioral variables that could alter results. The data were converted to a Microsoft Excel worksheet, and all calculations were done within the Excel program. Individual beam breaks for movement in the $\mathrm{x}$ and $\mathrm{y}$ planes were added up for each mouse to represent total ambulation, and beam breaks in the $\mathrm{z}$ plane were added up to obtain vertical activity within the 1-h time interval.

\section{TA tetanic contraction for functional assessment}

The TA assessment procedure followed the protocol listed in Hakim et al. ${ }^{23}$ Mice were anesthetized with ketamine/xylazine mixture $(137.5$ and $10 \mathrm{mg} / \mathrm{kg}$, respectively) administered intraperitoneally. The hind limb skin was removed to expose the TA muscle and patella. The length of muscle is measured after dissection, before placement of mouse, and the length is entered into the software. Care was taken to limit drying of the exposed muscle by constantly dampening the exposed muscles with a salinedampened Kimwipe drape. The TA distal tendon was then dissected out (left and right side per animal; average of both legs used for analysis $[n=12$ per cohort]), and a double square knot was tied around the tendon with 4-0 suture as close to the muscle as possible and then the tendon was cut.

Mice were then transferred to a thermal controlled platform and maintained at $37^{\circ} \mathrm{C}$. To stabilize the leg, a metal pin was placed behind the patellar tendon and the knee was secured to the platform with the distal TA tendon sutured to the level arm of the force transducer (Aurora Scientific, Aurora, Canada). An electrode was placed near the sciatic nerve to stimulate it. A warm-up protocol designed by Aurora Scientific was initiated where the resting tension was set at 3-4 g force and maintained for $5 \mathrm{~min}$, muscle stimulation at $1 \mathrm{~Hz}$ (three times-30 s apart), and an additional muscle stimulation at $150 \mathrm{~Hz}$ (three times-60 s apart).

Once the muscle was stabilized, the resting tension was set to a length (optimal length) where twitch contractions were maximal. After a 3-min rest period, the TA was stimulated at $50,100,150$, and $200 \mathrm{~Hz}$, allowing a 1-min rest between each stimulus. Following a 5-min rest, the muscles were then subjected to a series of 10 isometric contractions, occurring at 1-min intervals with a $10 \%$ stretch relengthening procedure. The duration of tetanic contraction lasts $200 \mathrm{~ms}$. After the eccentric contractions, the mice were euthanized and both TA muscles were dissected and frozen for histology and molecular studies. Maximum absolute force is determined from the plateau of the frequency/force relationship; force generated at $150 \mathrm{~Hz}$ frequency was used for the purposes of data analysis.

Formulas:

$$
\begin{aligned}
\text { Absolute Force }= & \text { Force at } 150 \mathrm{~Hz} * 9.8 \\
& (\text { where } 9.8 \mathrm{mN}=1 \mathrm{~g}) \\
\text { TA-Specific Force }= & \text { Absolute Force/Cross-Sectional } \\
& \text { Area } \\
\text { Cross-Sectional Area }= & \text { muscle weight }(\mathrm{g}) /[\mathrm{TA} \text { fiber } \\
& \text { length } \left.(\mathrm{cm}) \times 1.06\left(\mathrm{~g} / \mathrm{cm}^{3}\right)\right]
\end{aligned}
$$




\section{Diaphragm tetanic contraction for functional assessment}

Mice were euthanized and the diaphragm (DIA) was dissected with rib attachments and central tendon intact and placed in Kreb's-Henseleit $(\mathrm{K}-\mathrm{H})$ buffer $(118 \mathrm{mM} \mathrm{NaCl}$,

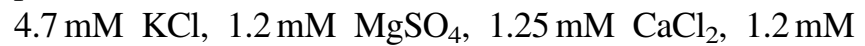
$\mathrm{KH}_{2} \mathrm{PO}_{4}, 25 \mathrm{mM} \mathrm{NaHCO} 3,11 \mathrm{mM}$ glucose) as previously described. ${ }^{20,24,25}$ A 2-4-mm-wide section of DIA was isolated per animal per cohort $(n=6)$. DIA strips were tied firmly with braided surgical silk (6/0; Surgical Specialties, Reading, PA) at the central tendon, and sutured through a portion of rib bone affixed to the distal end of the strip. Each muscle was transferred to a water bath filled with oxygenated $\mathrm{K}-\mathrm{H}$ solution that was maintained at $37^{\circ} \mathrm{C}$. The muscles were aligned horizontally and tied directly between a fixed pin and a dual-mode force transducer-servomotor (305C; Aurora Scientific). Two platinum plate electrodes were positioned in the organ bath so as to flank the length of the muscle. The muscle was stretched to optimal length for measurement of twitch contractions, and then allowed to rest for $10 \mathrm{~min}$ before initiation of the tetanic protocol. Once the muscle was stabilized, it was set to an optimal tension of $1 \mathrm{~g}$ and subjected to a warm-up, which consisted of three $1-\mathrm{Hz}$ twitches every $30 \mathrm{~s}$ followed by three $150-\mathrm{Hz}$ twitches every minute. After a 3-min rest period, the DIA was stimulated at $20,50,80,120,150$, and $180 \mathrm{~Hz}$, allowing a 2-min rest period between each stimulus, each with a duration of $250 \mathrm{~ms}$ to determine maximum tetanic force. Muscle length and weight were measured. The force was normalized for muscle weight and length. Maximum absolute force is determined from the plateau of the frequency/force relationship; force generated at $150 \mathrm{~Hz}$ frequency was used for the purposes of data analysis.

Formulas:

$$
\begin{aligned}
\text { Absolute Force }= & \text { Force at } 150 \mathrm{~Hz}^{*} 9.8 \\
& (\text { where } 9.8 \mathrm{mN}=1 \mathrm{~g}) \\
\text { DIA-Specific Force }= & \text { Absolute Force/Cross-Sectional } \\
& \text { Area } \\
\text { Cross-Sectional Area }= & \text { muscle weight }(\mathrm{g}) /[\mathrm{DIA} \text { fiber } \\
& \text { length } \left.(\mathrm{cm}) \times 1.06\left(\mathrm{~g} / \mathrm{cm}^{3}\right)\right]
\end{aligned}
$$

\section{Tissue processing}

Skeletal muscles were extracted from each mouse, placed on a saline-dampened gauze, then placed on 7\% gum tragacanth mounted wooden chucks and fresh frozen in cooled methyl butane. Organs were bisected and half were placed in $10 \%$ neutral buffered formalin followed by paraffin embedding for sectioning and hematoxylin and eosin (H\&E) staining. The other half of the organ was fresh frozen for subsequent molecular studies.

\section{Immunofluorescence}

Cryosections (12- $\mu \mathrm{m}$ thick) from the TA, gastrocnemius (GAS), quadriceps (QD), psoas major (PSO), gluteus
(GLUT), triceps (TRI), DIA, and heart (HRT) muscles were subjected to immunofluorescence staining for the hSGCA transgene via our previously used protocol. ${ }^{11}$ Sections were incubated with a rabbit monoclonal $\alpha-S G$ primary antibody (Catalog No. ab189254; Abcam, Cambridge, United Kingdom) at a dilution of 1:100. Four random $20 \times$ images covering the four different quadrants of the muscle section were taken using a Zeiss (Germany) AxioCam MRC5 camera. The percentage of fibers positive for $\alpha$-SG staining compared with controls was determined for each image and averaged for each muscle. Positive $\alpha$-SG fiber expression was defined as having at least $50 \%$ of the fiber staining brighter than the vehicle-treated $\mathrm{sgca}^{-/} \mathrm{LR}$ controls, as previously described. ${ }^{11}$ The test article was blinded at the time of injection. The operator who conducted the injections did not perform any analysis outside of the injection. There is no expression or residual protein in the untreated group, and so, it is clear which animal received treatment and which did not when observing under the scope, leaving blinding irrelevant for immunofluorescence quantification. To mitigate variability in intensity, images were taken at the same exposure.

Fibers counted were defined by the structural appearance of the fiber's cross section. To facilitate scoring, National Institutes of Health (NIH) ImageJ with the Cell Counter plugin was used to count total fibers. By convention, a "Type \#" and color were selected to score/mark positive fibers. The Cell Counter tracked the counts as fibers were selected. Positive fibers were scored based on the original image exposure; there was no adjustment to the brightness or contrast of any image during the positive image scoring process. Once positive fiber selections were completed, the brightness and contrast of the image were adjusted to facilitate visualization of the negative fibers. No additional positive fibers were scored once the brightness and contrast were adjusted. The remaining fibers were scored as negative using a different "Type \#" and color for the score/mark. Once scoring was complete, "Export Image" was selected from the Cell Count workspace. This image was saved separately as an annotated .jpeg image. Total fiber counts were determined after all fibers were counted. Quantification data of immunofluorescentpositive fibers expressing $\alpha$-SG protein are reported as mean \pm standard of error of the mean, with six mice per treatment group.

\section{Western blot analysis}

Western blots were performed according to our previously used protocol, with several modifications specific for each antibody used. ${ }^{11}$ Samples from WT C57BL/6 mice, sgca ${ }^{-/-}$LR mice, and vector-dosed $\mathrm{sgca}^{-/-}$mice were used for each Western blot. A 1:10,000 dilution of a rabbit monoclonal $\alpha$-SG antibody (Catalog No. ab189254; Abcam) was used to detect $\alpha$-SG in all blots. For the protein loading control, a 1:5,000 dilution of a mouse monoclonal $\alpha$-actinin antibody (Catalog No. A7811; Sigma-Aldrich) 
and a 1:1,000 dilution of a rabbit monoclonal mouse vinculin antibody (Catalog No. 70062; Invitrogen) were used to detect $\alpha$-actinin and vinculin in muscle-tissue and nonmuscle-tissue blots, respectively. Anti-mouse (Cata$\log$ No. AP308P; Millipore) and anti-rabbit (Catalog No. 656120; Life Technologies) secondary horseradish peroxidase antibodies were used for enhanced chemiluminescence immunodetection. For muscle-tissue blots, densitometry quantification was determined using ImageQuant TL analysis software, which quantified the raw densitometric units for each protein band at the appropriate size.

\section{Morphometric analysis}

H\&E staining was performed on $12-\mu \mathrm{m}$-thick cryosections of muscle from 16- to 17-week-old WT C57BL/6 mice $(n=6)$, $\mathrm{sgca}^{-1-}$ LR mice $(n=6)$, and scAAVrh74.tMCK.hSGCA 16to 17 -week-old treated $\mathrm{sgca}^{-/-}$mice $(n=6$ per dose, 12 weeks post-treatment) for analysis. The percentage of myofibers with CN was determined in the TA, GAS, QD, GLUT, PSO, and TRI muscles. In addition, muscle fiber diameters were measured using Feret's diameter in the TA, GAS, QD, TRI, and PSO muscles. There was a range of 3,000 to 6,000 fibers quantified per muscle from each treatment group and from the control cohorts. Four random $20 \times$ images per muscle per animal were taken with a Zeiss AxioCam MRC5 camera. Centrally nucleated fibers were quantified using NIH ImageJ software, and fiber diameters were measured using Zeiss AxioVision LE4 software.

\section{Picrosirius red stain and collagen quantification}

Picrosirius red staining was performed to determine the levels of collagen deposition in muscle tissue using a previously published protocol from our laboratory. ${ }^{12}$ Staining was performed on $12-\mu \mathrm{m}$ cryosections from 16 - to 17-week-old WT C57BL/6 $(n=6), \mathrm{sgca}^{-/-}$LR $(n=6)$, and scAAVrh74.tMCK.hSGCA 16- to 17-week-old treated $\mathrm{sgca}^{-/-}$( $n=6$ per dose) GLUT, PSO, TRI, and DIA muscles. Four $20 \times$ images were taken per muscle per mouse, and the amount of collagen deposition was determined with the ImageJ software program. The mean percent collagen for each muscle was calculated for all groups.

\section{Biodistribution qPCR analysis}

TaqMan qPCR was performed to quantify the number of vector genome copies as previously described. ${ }^{11,26,27} \mathrm{~A}$ vector-specific primer probe set was used to amplify a sequence of the intronic region directly downstream from the tMCK promoter that is unique and located within the scAAVrh.74.tMCK.hSGCA transgene cassette. The following primers and probe were used in this study: tMCK intron forward primer 5'-GTG AGG CAC TGG GCA GGT AA-3'; tMCK intron reverse primer 5'-ACC TGT GGA AAA GGC AAA G-3'; and tMCK intron probe 5'-6FAMATC AAG GTT ACA AGA CAG-GTT TAA GGA CAA
TAG AAA-tamra-3' (Integrated DNA Technologies). Copy number was reported as vector genomes per microgram of genomic DNA and as copies per diploid genome. The analysis was performed in triplicate per sample $(n=2)$.

\section{Hematology}

Whole blood was retrieved from cardiac puncture for blood chemistries from treated WT and knockout mice. Blood was collected in a serum separating tube and centrifuged for $10 \mathrm{~min}$ at $15,000 \mathrm{rpm}$. Serum was collected, frozen, and sent to Charles River Laboratories for processing and assessment of serum chemistry. Due to limited sample volume, liver enzymes and glucose chemistries were prioritized.

\section{Serum CK measurement}

Levels of CK were measured in the sera of WT C57BL/6 mice $(n=6), \mathrm{sgca}^{-/-}$LR mice $(n=6)$, and scAAVrh74.tMCK.hSGCA-treated $\mathrm{sgca}^{-/-}$mice $(n=6$ per dose) using the CK SL assay and the corresponding manufacturer's protocol (Catalog No. 32610; Sekisui Diagnostics, Charlottetown, PE, Canada). Briefly, $25 \mu \mathrm{L}$ of serum was mixed with $1 \mathrm{~mL}$ of the working reagents and added to a cuvette. A kinetic assay was set on the spectrophotometer to measure the absorbance at $340 \mathrm{~nm}$ every $30 \mathrm{~s}$ for $180 \mathrm{~s}$. CK levels were calculated using the absorbance readings and the equation listed below:

$$
\begin{aligned}
\mathrm{U} / \mathrm{L} & =[(\Delta \text { Abs. } / \mathrm{min}) * 1.025 * 1,000] /[1 * 6.22 * 0.025] \\
& =(\Delta \text { Abs. } / \mathrm{min}) * 6,592 .
\end{aligned}
$$

\section{Histopathology}

At necropsy, muscles were fresh frozen in liquid nitrogen-cooled methyl butane, and tissues were stained with H\&E. All other organs were harvested and fixed in formalin and embedded in paraffin. Slides and all tissues were sent to GEMpath, Inc., for formal review by a veterinary pathologist.

\section{Statistical analysis}

Data were analyzed using a one-way ANOVA with multiple comparisons between groups assessed by Tukey's or Dunnett's post hoc analysis test using GraphPad Prism 5 (GraphPad Software, La Jolla, CA), unless otherwise specified.

\section{RESULTS}

\section{Dose-escalation study of scAAVrh74.tMCK.hSGCA systemic gene transfer to sgca $^{-/}$mice}

To determine the safest and most efficacious dose, we investigated the delivery of three separate doses of vector 
in a dose-escalation study, where the lateral tail vein of 4week-old $\mathrm{sgca}^{-/-}$mice were treated with $1.0 \times 10^{12} \mathrm{vg}$ total dose $\left(5.0 \times 10^{13} \mathrm{vg} / \mathrm{kg}\right), 3.0 \times 10^{12} \mathrm{vg}$ total dose $\left(1.0 \times 10^{14}\right.$ $\mathrm{vg} / \mathrm{kg})$, or $6.0 \times 10^{12} \mathrm{vg}$ total dose $\left(2.0 \times 10^{14} \mathrm{vg} / \mathrm{kg}\right)$ of scAAVrh74.tMCK.hSGCA, corresponding to low, intermediate, and high doses. Mice were euthanized 12 weeks postgene transfer to assess hSGCA transgene expression in the TA, GAS, QD, GLUT, PSO, TRI, DIA, and HRT muscles using immunofluorescence. Robust expression of hSGCA was observed at the sarcolemma across skeletal tissues (Fig. 1A).

Quantitative analysis of positive fiber expression demonstrated a dose-dependent increase in expression in each muscle examined (Fig. 1B). Mean hSGCA expression assessed by immunohistochemistry in mice treated with the lowest tested dose of $1.0 \times 10^{12} \mathrm{vg}$ total dose was $70.07 \% \pm 3.71 \%$ overall expression of positive fibers in the skeletal muscles. Mean hSGCA overall expression in mice treated with the intermediate dose of $3.0 \times 10^{12} \mathrm{vg}$ total dose was $85.35 \% \pm 2.36 \%$ in all skeletal muscles. Mean hSGCA expression in mice treated with the highest dose of $6.0 \times 10^{12}$ vg total dose was $93.86 \% \pm 2.02 \%$ in all skeletal muscles. Moreover, Western blots shown in Fig. 1C confirm protein expression across muscle tissues in treated mice at the lowest dose tested; the hSGCA expression in the HRT muscle remained at least $69 \%$ of WT for the low, middle, and high doses.

Histopathological characteristics of both humans and mice devoid of $\alpha$-SG protein include $\mathrm{CN}$, irregularities in fiber size distribution, necrosis, and fibrosis. ${ }^{1,7} \mathrm{H} \& \mathrm{E}$ staining was used to visualize muscle morphology, including fiber size and $\mathrm{CN}$ (Fig. 2). As shown in Fig. 2A and $\mathrm{B}$, a normalization of fiber size distribution, similar to that observed in WT controls, was observed in the TA, QD, TRI, GLUT, and PSO of scAAVrh74.tMCK.hSGCAtreated $\mathrm{sgca}^{-/}$mice compared with vehicle-treated $\mathrm{sgca}^{-/-}$ $\left(\mathrm{sgca}^{-/-} \mathrm{LR}\right)$ controls. The average diameter size of fibers was significantly increased at all doses in the TA, QD, and TRI muscles compared with $\mathrm{sgca}^{-/}$LR control mice (Supplementary Table S1).

In $\mathrm{sgca}^{-/-}$mice treated with scAAVrh74.tMCK.hSGCA, reduction in $\mathrm{CN}$ was also observed. The effects of scAAVrh74.tMCK.hSGCA on CN were muscle- and dose-dependent (Fig. 2C). Significant reductions in CN, dependent on dose, were observed in TA, GAS, QD, and TRI. A high dose of $6.0 \times 10^{12} \mathrm{vg}$ resulted in statisti- cally significant differences in $\mathrm{CN}$ compared with the low and intermediate dose $\left(1.0 \times 10^{12}\right.$ and $3.0 \times 10^{12} \mathrm{vg}$, respectively) in GAS. Moreover, mice treated with $6.0 \times 10^{12}$ vg had significantly less $\mathrm{CN}$ compared with mice treated at $3.0 \times 10^{12} \mathrm{vg}$ in QD, GLUT, and TRI $6.0 \times 10^{12} \mathrm{vg}$. However, when the data were collapsed across all skeletal muscles, $\mathrm{sgca}^{-1-}$ LR mice had $68.72 \% \pm 3.01 \%$ fibers with centrally located nuclei. After treatment with scAAVrh74.tMCK.hSGCA, the overall value of CN across all muscle tissue was reduced with the lowest dose of scAAVrh74.tMCK.hSGCA, resulting in $55.60 \% \pm 3.25 \%$ of skeletal muscle fibers showing centrally located nuclei. Mice treated with the intermediate dose had $61.85 \% \pm 4.00 \%$ of muscle fibers with $\mathrm{CN}$, while the nucleation of muscle fibers treated with the highest dose was reduced to $37.93 \% \pm 12.46 \%$.

Fibrosis, where the tissue is overcome by collagen, often occurs in the muscles of patients with LGMD, leading to the formation of scar tissue. As the GLUT and PSO muscles are critical for ambulation, reduction in fibrotic content is particularly important to evaluate in these muscles. Fibrosis was assessed using a picrosirius red stain to detect collagen I and III content, as a marker of fibrosis. As shown in Fig. 3A, a robust reduction in red staining was observed in $\mathrm{sgca}^{-/-}$mice after treatment with scAAVrh74.tMCK.hSGCA. Quantification revealed a significant reduction in collagen content across all muscles in scAAVrh74.tMCK.hSGCA-treated $\mathrm{sgca}^{-1-}$ mice compared with $\mathrm{sgca}^{-/-}$LR mice, with the exception of the DIA for the intermediate dose. This exception could be attributed to higher fibrosis baseline levels in this particular group, and is consistent with the improvement observed in the mice that received the other two doses (Fig. 3B). Together, these data demonstrate successful systemic gene transfer of the hSGCA transgene as indicated by robust expression in muscle tissues and improvement in histopathological hallmarks associated with the lack of $\alpha$-SG protein in $\mathrm{sgca}^{-1-}$ mice.

\section{scAAVrh74.tMCK.hSGCA improves diaphragm and TA muscle function and increases locomotor ability}

As weakness and loss of function of proximal muscles are major symptoms of LGMD2D/R3, and respiratory failure is the leading cause of death in LGMD2D/R3, ${ }^{5,28}$ improving the functionality and strength of the TA and

Figure 1. Systemic treatment with scAAVrh74.tMCK.hSGCA promotes robust transgene expression. (A) $\alpha$-Sarcoglycan immunofluorescence stain of multiple muscles from mice systemically (intravenous) treated with $1.0 \times 10^{12} \mathrm{vg}, 3.0 \times 10^{12} \mathrm{vg}$, or $6.0 \times 10^{12} \mathrm{vg}$ total dose ( $n=6$ per group). Muscle fibers expressing the $\alpha$-sarcoglycan 12 weeks post-treatment ranged from $70 \%$ to $93 \%$ compared with untreated controls ( $n=6 /$ group). Scale bar $=100 \mu \mathrm{m}$. (B) 0 uantitative analysis of immunohistochemistry as assessed by measuring percent fiber expression in vector-treated mice across muscle samples. Data are reported as mean \pm standard of error of the mean ( $n=6$ for each cohort). Data were analyzed by one-way ANOVA followed by Tukey's post hoc analysis. ${ }^{* * * *} p<0.0001$, ${ }^{* * *} p<0.001,{ }^{*} p<0.02$ compared with low-dose $\left(1 \times 10^{12} \mathrm{vg}\right)$ cohort. (C) Representative Western blots of muscles and densitometry quantification from treated sgca $^{-/}$mice confirm hSGCA protein expression ( $n=5$ for low dose, and $n=2$ for middle and high dose). For the densitometry quantification, data are reported as mean \pm standard of error of the mean ( $n=5$ for low dose, and $n=2$ for middle and high dose). DIA, diaphragm; GAS, gastrocnemius; GLUT, gluteus; HRT, heart; PSO, psoas major; QD, quadriceps; TA, tibialis anterior; TRI, triceps; WT, wild type. 


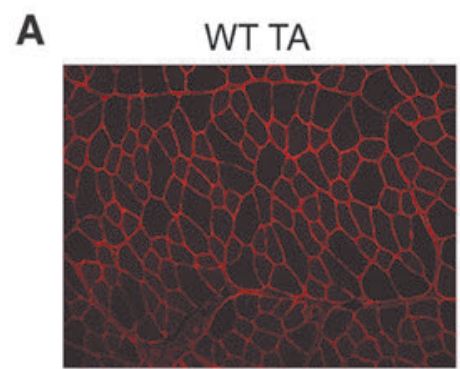

TA
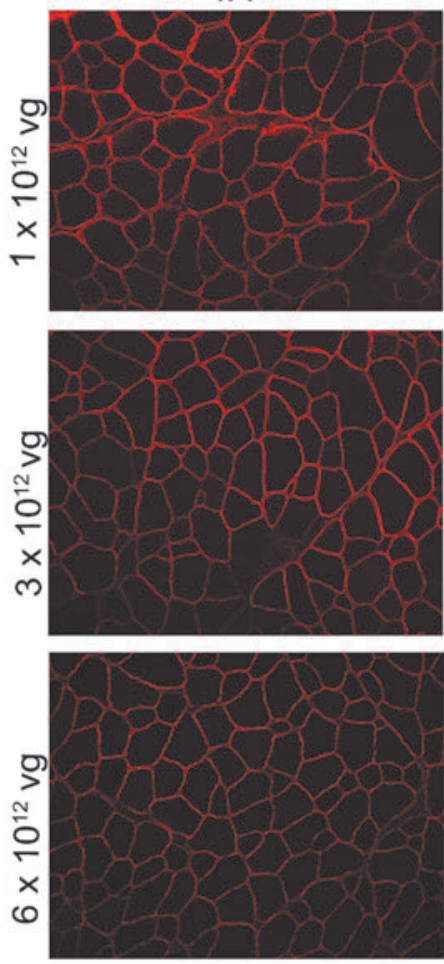

B

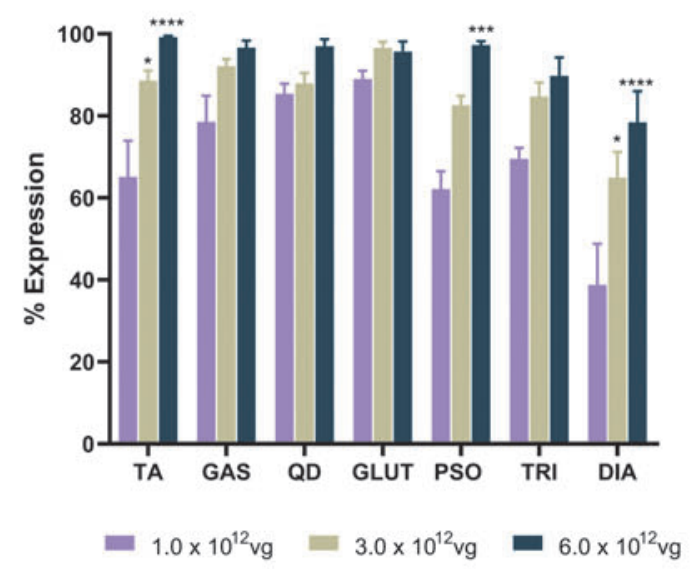

TRI
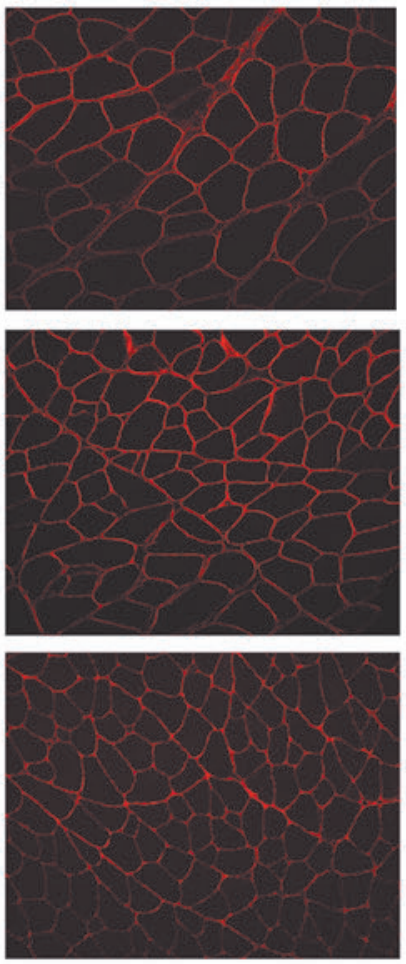

C

\begin{tabular}{|c|c|}
\hline $\begin{array}{l}\text { Mouse 44439 } \\
1.00 \times 10^{2} v 2\end{array}$ & $\begin{array}{l}\text { Mouse e } 4444 \\
3.0 \times 10^{2} 2 \mathrm{~g}\end{array}$ \\
\hline & \\
\hline
\end{tabular}
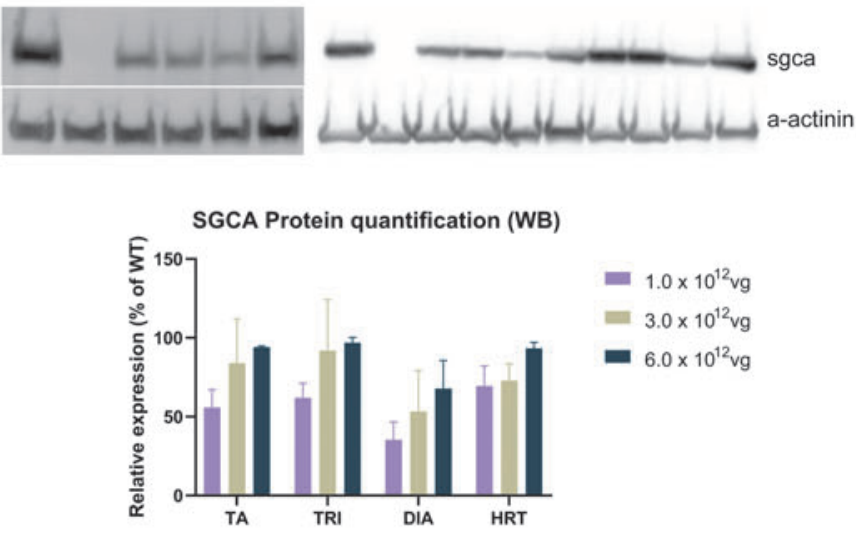
DIA are imperative to increasing the length and quality of life in patients with LGMD2D/R3. As an experimental tool, strips of the DIA and whole TA muscles were used to confirm the correlation between hSGCA expression and muscle strength. As shown in Fig. 4A and $\mathrm{B}$, a deficit in specific force and resistance to contraction-induced injury was identified in the TA and specific force in the DIA muscles of $\mathrm{sgca}^{-/-}$LR mice compared with WT mice.

TA muscles of $\mathrm{sgca}^{-/-}$mice exhibited a significant functional deficit of $44 \%$ in the reduction of specific force output compared with WT mice $\left(161.6 \pm 8.20 \mathrm{mN} / \mathrm{mm}^{2}\right.$ vs. $291.7 \pm 6.17 \mathrm{mN} / \mathrm{mm}^{2}$, respectively; $p<0.0001$ ), as well as a greater loss of force from that produced following a rigorous eccentric contraction protocol $(44.0 \% \pm 6.0 \%$ loss in $\mathrm{sgca}^{-/-}$LR mice; $18.0 \% \pm 1.0 \%$ loss in WT mice; $p<0.0001$ ) (Fig. 4A). Twelve weeks following tail vein delivery, we noted a significant improvement after treatment with low, intermediate, and high doses of scAAVrh74.tMCK.hSGCA in specific force output, which increased to $218 \pm 11.94,227 \pm 11.7$, and $255 \pm 11.7 \mathrm{mN} /$ $\mathrm{mm}^{2}$, respectively $(p<0.0001)$. Resistance to injury following an eccentric contraction protocol also improved compared with vehicle-treated $s \mathrm{sa}^{-/-} \mathrm{LR}$ mice, in which the low-, intermediate-, and high-dose-treated mice only lost $22.0 \% \pm 4.0 \%, 22.0 \% \pm 3.0 \%$, and $12.0 \% \pm 1.0 \%$, respectively $\left(p<0.0001\right.$ compared with $\mathrm{sgca}^{-/-}$LR mice) (Fig. 4A).

In the DIA of $\mathrm{sgca}^{-/-}$LR mice, the specific force generated showed a $41 \%$ reduction in strength compared with WT mice $\left(131.5 \pm 12.07 \mathrm{mN} / \mathrm{mm}^{2}\right.$ vs. $223.8 \pm 15.85 \mathrm{mN} /$ $\mathrm{mm}^{2}$ ). A significant improvement in force was observed following treatment with scAAVrh74.tMCK.hSGCA at all three doses, where the specific force of the DIA in low-dosed mice increased to $179.2 \pm 21.03 \mathrm{mN} / \mathrm{mm}^{2}$ $(p<0.05)$, in intermediate-dosed mice increased to $201.2 \pm 22.94 \mathrm{mN} / \mathrm{mm}^{2}(p<0.05)$, and in high-dosed mice increased to $261.46 \pm 9.73 \mathrm{mN} / \mathrm{mm}^{2}(p<0.001)$ (Fig. 4B). These data show that the TA and DIA muscles in $\mathrm{sgca}^{-/-}$ mice have a significant deficit in force when compared with WT mice (in TA and DIA $\mathrm{sgca}^{-/}$LR vs. WT, $p<0.0001$ and $p<0.01$, respectively). However, after the delivery of scAAVrh74.tMCK.hSGCA, functional recovery was achieved.

Additional symptoms of LGMD2D/R3 include exercise intolerance and reduced activity and ambulation, possibly due to muscle damage, resulting in muscle loss and fatigue. ${ }^{4-6}$ To assess the level of physical activity, $\mathrm{sgca}^{-/-}$
LR and WT mice were subjected to an open-field activity protocol similar to that used in previous reports. ${ }^{20,21}$ The ambulation-related activities of mice were monitored to determine if the lack of SGCA in the $\mathrm{sgca}^{-/-}$mouse leads to a decrease in ambulation compared with WT mice. The graphs in Fig. 4C depict a reduction in ambulation and vertical rearing in the $\mathrm{sgCa}^{-/-}$mouse model compared with WT controls. The mean horizontal ambulatory beam breaks recorded in the $\mathrm{sgca}^{-/}$LR mice were 2,000 \pm 159 beam breaks per hour, a $77.5 \%$ decrease in ambulation compared with $8,911 \pm 1,193$ beam breaks per hour in WT controls. The mean vertical rearing beam breaks recorded in the $\mathrm{sgca}^{-/}$mice were $24.75 \pm 11.47$ beam breaks per hour, a $97 \%$ decrease in vertical rearing compared with $803.3 \pm 55.03$ beam breaks per hour in WT mice.

After treatment with scAAVrh74.tMCK.hSGCA, the ambulation and vertical rearing activities of mice increased 12 weeks postgene transfer. The mean horizontal ambulation increased to $3,595 \pm 55.03$ beam breaks per hour in mice treated with $1.0 \times 10^{12} \mathrm{vg}$ total dose, $5,238 \pm 861.9$ beam breaks per hour in mice treated with $3.0 \times 10^{12} \mathrm{vg}$ total dose, and $6,487 \pm 467.9$ beam breaks per hour in mice treated with $6.0 \times 10^{12} \mathrm{vg}$ total dose. The mean vertical rearing activity increased to $377 \pm 146.1$ beam breaks per hour in mice treated with $1.0 \times 10^{12} \mathrm{vg}$ total dose, $321 \pm 126.1$ beam breaks per hour in mice treated with $3.0 \times 10^{12} \mathrm{vg}$ total dose, and $448.8 \pm 53.43$ beam breaks per hour in mice treated with $6.0 \times 10^{12} \mathrm{vg}$ total dose (Fig. 4C). The physical activities of the vectortreated mice showed improvement from $44 \%$ to $69 \%$ in ambulation and $92 \%$ to $94 \%$ in vertical rearing compared with $\mathrm{sgca}^{-/-}$LR mice. In addition, serum CK levels were significantly reduced in all treated groups compared with untreated mice (Fig. 4D). Together, these data show that the delivery of hSGCA restores the physical activity and protects against the breakdown of muscle in $\mathrm{sgca}^{-/}$mice.

\section{Safety and biodistribution analysis of scAAVrh74.tMCK.hSGCA}

As a safety provision, blood chemistries and hematology studies were performed on vector-dosed $\mathrm{sgca}^{-/}$and WT mice. All values were within the normal reference ranges for mice (Fig. 5). Furthermore, tissue sections of all organs stained with $\mathrm{H} \& \mathrm{E}$ from scAAVrh74.tMCK.hSGCA-dosed $\mathrm{sgca}^{-/-}$and WT mice were sent to a veterinary pathologist for formal review of potential toxicity. No organs showed abnormalities in any sample from any of the scAAVrh74.tMCK.hSGCA-dosed $\mathrm{sgca}^{-/-}$and WT mice. In

Figure 2. Improvement in muscle morphology by scAAVrh74.tMCK.hSGCA is independent of dose in sgca ${ }^{-1}$ mice. (A) Hematoxylin and eosin images of various muscles from $\mathrm{sgca}^{-/}$mice treated with $1.0 \times 10^{12} \mathrm{vg}, 3.0 \times 10^{12} \mathrm{vg}$, and $6.0 \times 10^{12} \mathrm{vg}$ of scAAVrh74.tMCK.hSGCA ( $n=6 /$ group). Representative $20 \times$ images show a dramatic reduction in centralized nuclei and an overall normalization of fiber size independent of treatment dose. Scale bar $=100 \mu \mathrm{m}$. (B) Quantification confirming myofiber diameter normalization of various muscles in vector-treated groups compared with vehicle-treated mice (sgca ${ }^{-/}$LR) and WT controls ( $n=6 /$ group). (C) Quantification of centrally located nuclei in muscles of treated mice compared with $s g c a^{-/-}$LR and WT controls ( $n=6 /$ group).

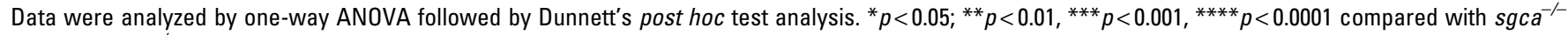
LR mice. sgca ${ }^{-/}$LR, lactate Ringer's solution-treated mice. 

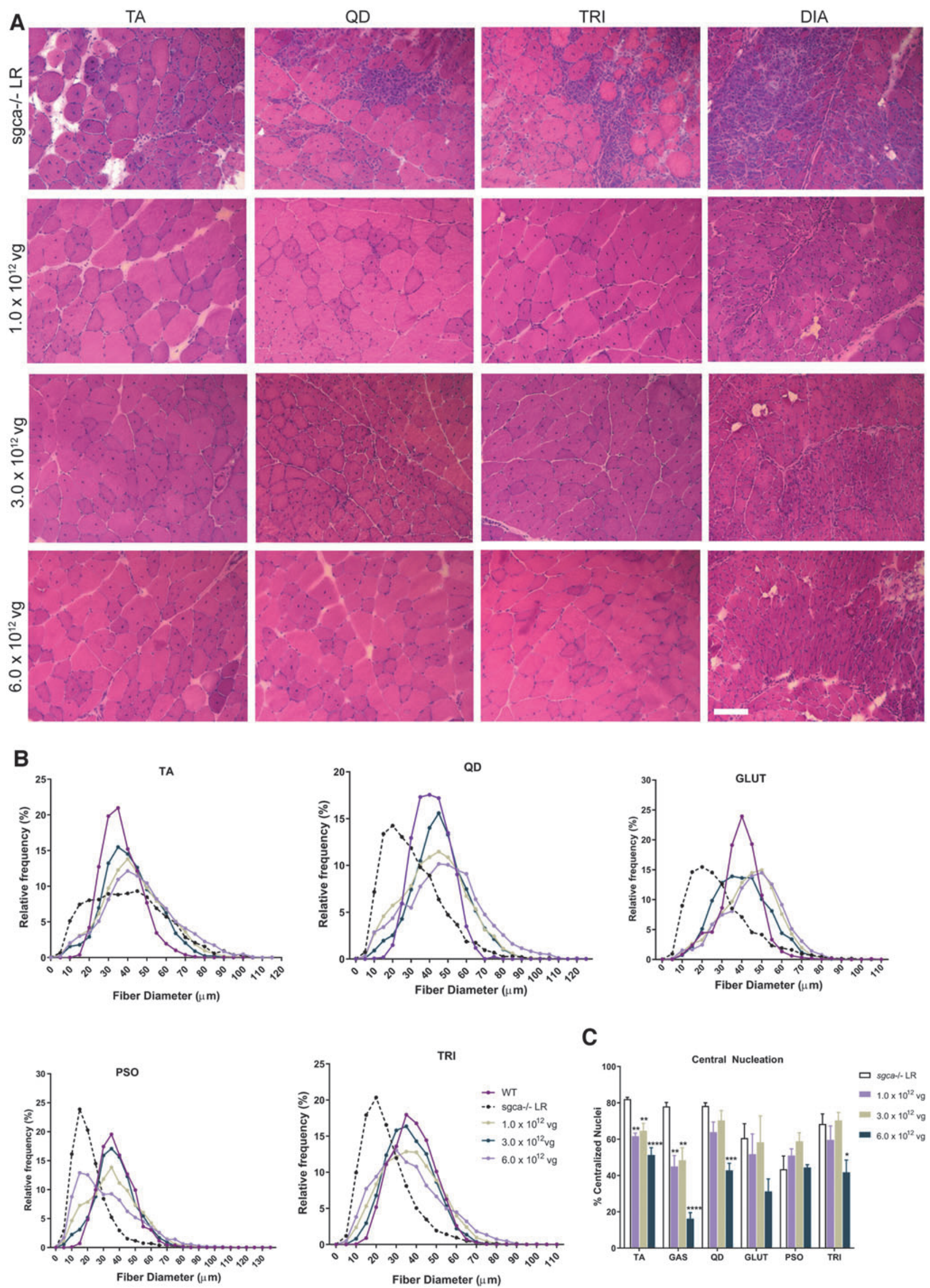

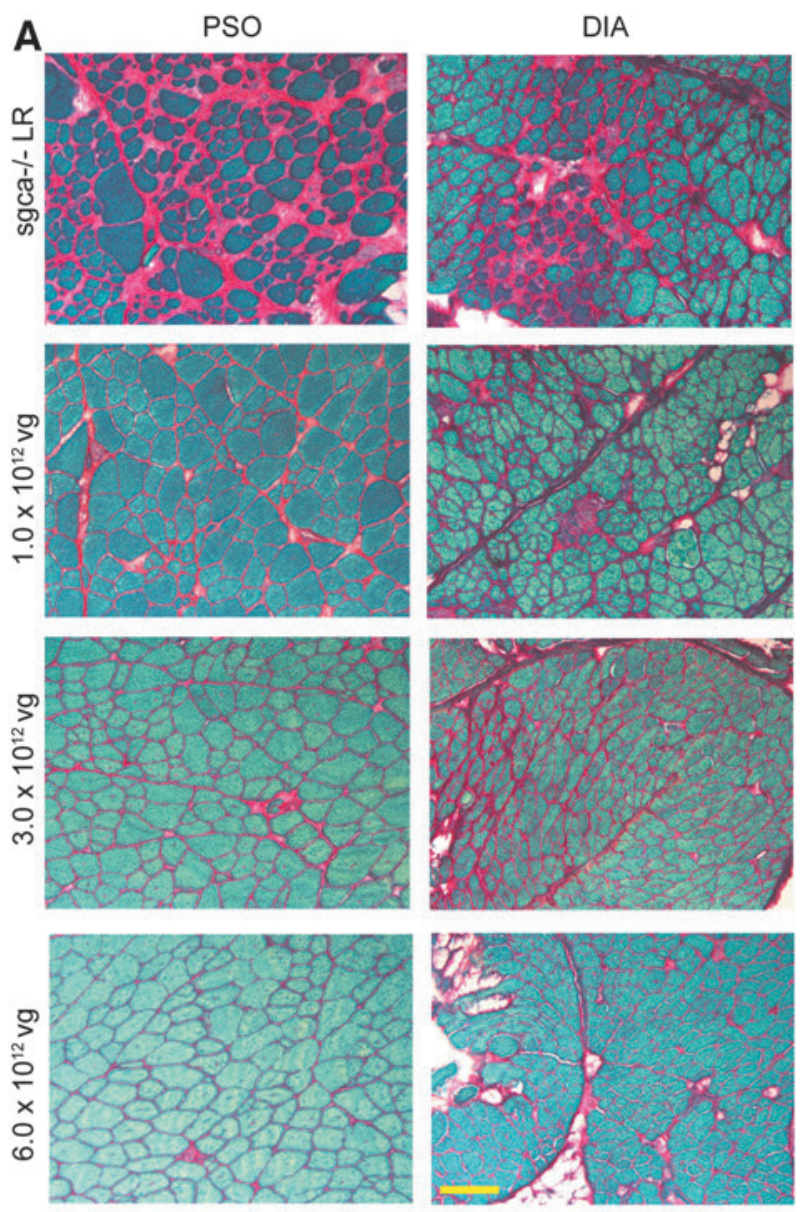

B

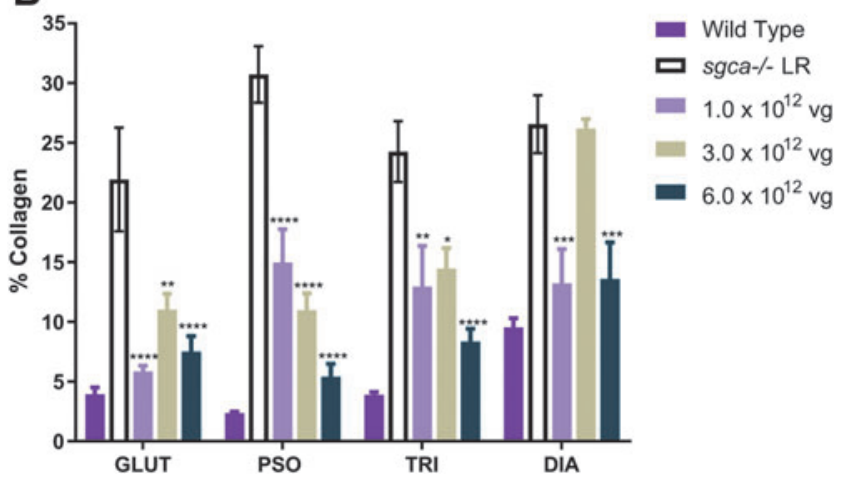

Figure 3. Reduction in fibrosis in $\mathrm{sgca}^{-/}$mice treated with scAAVrh74.tMCK.hSGCA. (A) Picrosirius red staining shows reduced fibrosis in scAAVrh74.tMCK.hSGCA-treated mice, indicated by a decrease in collagen deposition compared with vehicle-treated ( $\left.\mathrm{sgca}^{--} \mathrm{LR}\right)$ mice in PSO and DIA. Representative 20×images shown. Scale bar $=100 \mu \mathrm{m}$. (B) Quantification of collagen levels in various muscles confirms reduction in collagen levels in all three treated groups compared with $s g c a^{-/}$LR and WT controls ( $n=6 /$ group). Data were analyzed by one-way ANOVA followed by Dunnett's post hoc analysis. ${ }^{*} p<0.05,{ }^{* *} p<0.01,{ }^{* * *} p<0.001$, ${ }^{* * * *} p<0.0001$, compared with vehicle-treated sgca $^{-1}$ mice. addition to efficacy, these data demonstrated that the systemic gene transfer for all three doses of scAAVrh74.tMCK.hSGCA was well-tolerated, safe, and nontoxic to $\mathrm{sgca}^{-/-}$and WT mice.

Vector biodistribution qPCR was performed to quantify vector genome presence following delivery of scAAVrh74.tMCK.hSGCA (Supplementary Fig. S1A). Vector-specific tMCK.hSGCA primer probe sets were used to detect vector genomes in all muscles and organs tested from the scAAVrh74.tMCK/hSGCA-dosed $\mathrm{sgca}^{-/-}$ mice. As expected, vector genomes were present in every tissue tested, with the highest copy number in the liver, followed by muscles, confirming successful transduction. Transgene expression was detected only in targeted tissues (all muscles) and was absent in other (nonmuscle) organs, except for the liver (Supplementary Fig. S1B).

\section{DISCUSSION}

LGMD2D/R3 is caused by mutations in the SGCA gene, which leads to complete or reduced loss of functional $\alpha$-SG protein and concomitant loss of other structural components of the dystrophin-associated protein complex. ${ }^{3,4,6}$ The loss of the $\alpha$-SG protein leads to a progressive muscular dystrophy with deteriorating muscle function and respiratory abnormalities. ${ }^{4,6}$ To date, there are no disease-modifying therapies for LGMD2D/R3. ${ }^{5}$ Given the monogenetic nature of the disease, gene transfer therapy has emerged as a promising treatment modality for patients with LGMD2D/R3.

In our recent Phase I/II LGMD2D/R3 intravascular gene transfer (via isolated limb infusion [ILI]) trial, we demonstrated improvement in force in target muscles; however, there was no improvement in walk time due to the inability to target hip girdle muscles. ${ }^{14}$ Thus, the successful systemic (intravenous) gene transfer of scAAVrh74.tMCK.hSGCA in the SGCA knockout $\left(\mathrm{s} \mathrm{cal}^{-/}\right)$mice indicates the potential for systemic treatment of LGMD2D/R3 rather than the ILI procedure. The goal of this study was to evaluate the safety and efficacy of ascending doses delivered systemically. Using the lateral tail vein of mice to deliver escalating doses of the hSGCA gene, we were able to target multiple muscles in both forelimbs and hind limbs, showing robust $\alpha$-SG expression in the mice at all three doses. Most importantly, the vital diaphragm muscle also showed hSGCA gene expression after delivery, and $\alpha-S G$ protein expression was also confirmed through Western blot analysis in all muscles of all three dosing cohorts. The cardiac muscle in mice also showed $\alpha$-SG protein expression after treatment. Notably, efficacy was observed at the lowest dose tested and safety was not a concern at the highest dose tested.

Although cardiac defects are sporadically observed in patients with LGMD2D/R3, having additional cardiac 

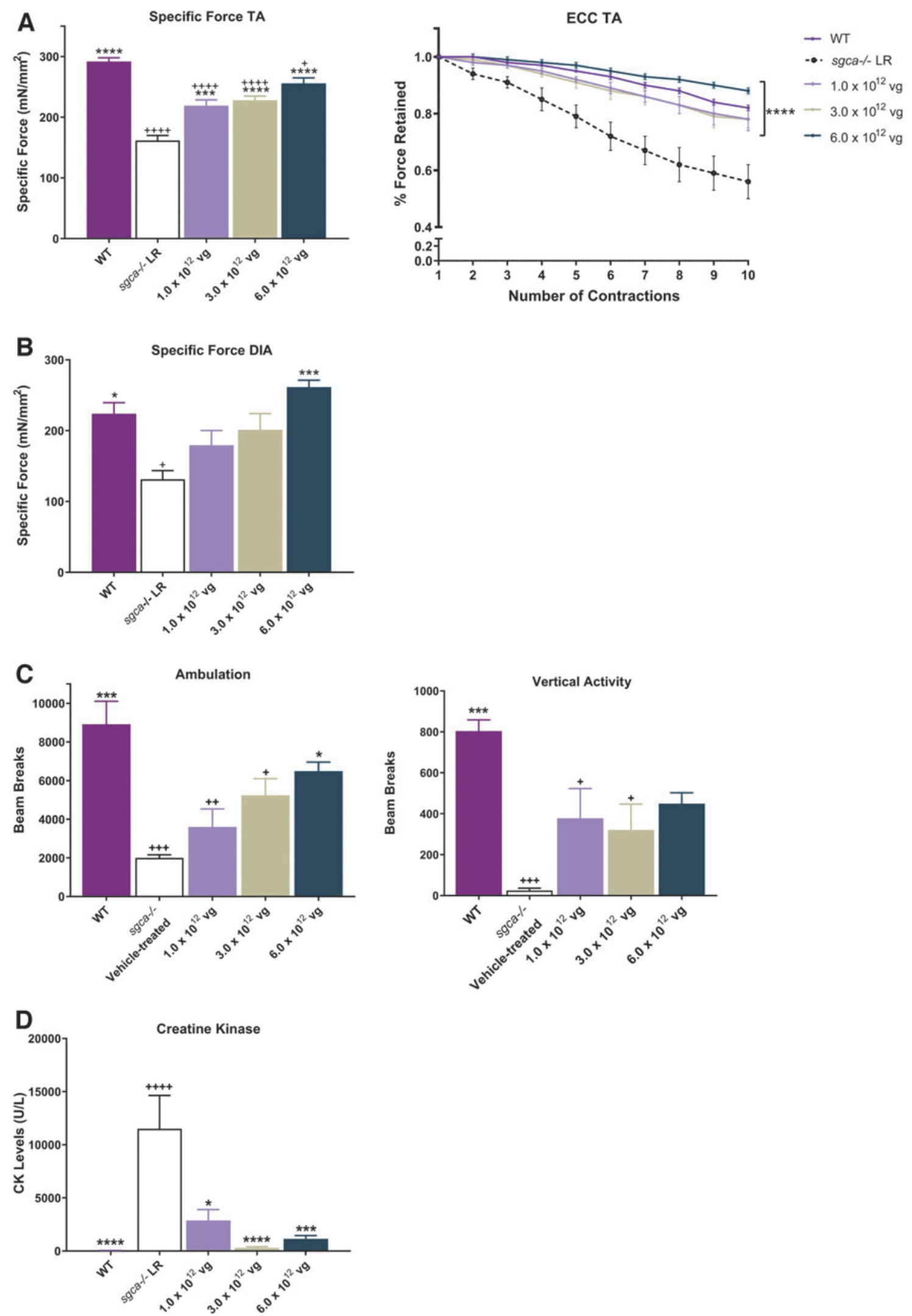

Figure 4. Functional benefits to skeletal muscle after treatment with scAAVrh74.tMCK.hSGCA. (A) Following 12 weeks of treatment, specific force and resistance to contraction-induced damage of TA muscles (both left and right) were measured (data were normalized to TA weight). The quantification of specific force and eccentric contraction was increased in all vector-treated $\mathrm{sgca}^{-/-}$mice (with minimal difference between doses) compared with vehicletreated ( $\left.\mathrm{sgca}^{-/} \mathrm{LR}\right)$ mice ( $n=6 /$ group, average of both legs used for analysis [total $n=12$ ]). (B) Diaphragm muscle strips were harvested to measure specific force. Following 12 weeks of treatment, the force was significantly increased in treated mice compared with $\mathrm{sgca}^{-/-}$LR mice. (C) Following 12 weeks of

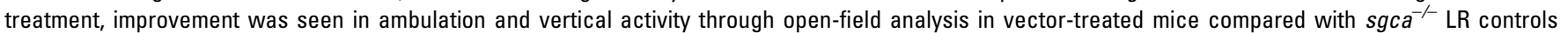
( $n=6 /$ group). (D) CK levels in serum decreased in all vector-treated groups compared with $s_{\text {sca }}{ }^{-/}$LR controls. Data were analyzed by one-way ANOVA followed by Tukey's post hoc analysis for multiple comparisons. ${ }^{*} p<0.05$, ${ }^{* *} p<0.01,{ }^{* * *} p<0.001$, ${ }^{* * *} p<0.0001$ compared with sgca ${ }^{-/}$LR mice, unless noted. ${ }^{+} p<0.05,{ }^{++} p<0.01,{ }^{+++} p<0.001,{ }^{++++} p<0.0001$ compared with WT mice. CK, creatine kinase; ECC, eccentric contraction. 

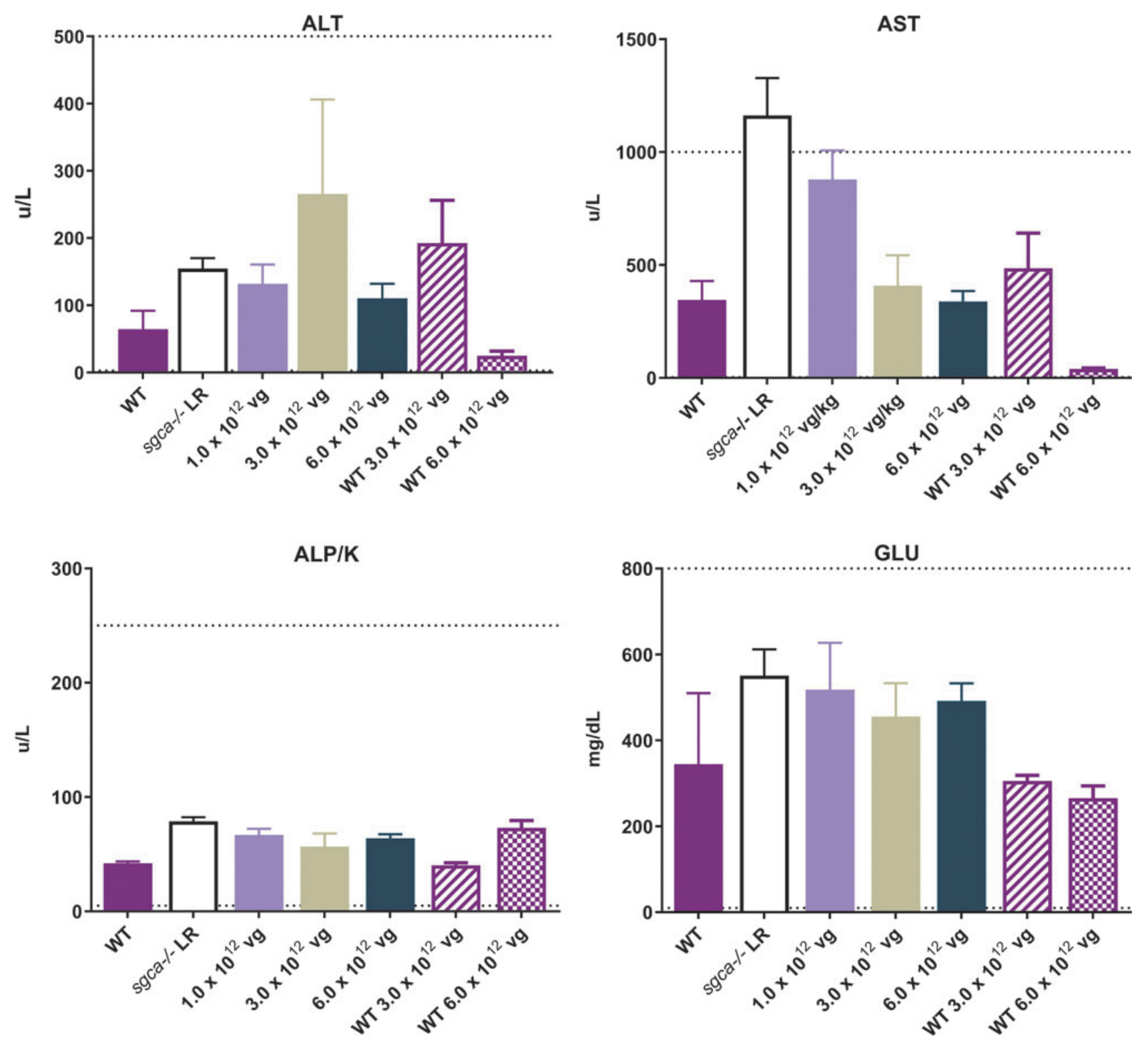

Figure 5. No evidence of toxicity through blood chemistries after treatment with scAAVrh74.tMCK.hSGCA. Liver enzymes (ALT, AST, and ALP/K) and blood GLU levels were analyzed for toxicity ( $n=6 /$ group). All chemistry values of treated mice were within the normal/healthy limits of mice as indicated by the dotted lines. ALP/K, alkaline phosphatase; ALT, alanine aminotransferase; AST, aspartate aminotransferase; GLU, glucose.

protection after treatment can be beneficial. Prior studies indicate that the $\mathrm{sgca}^{-/}$mice do not exhibit gross morphological changes in heart at up to 8 months of age. ${ }^{29}$ However, we hypothesize that the increase in ambulatory motor activity as a result of scAAVrh74.tMCK.hSGCA further leads to engagement of the heart, in turn leading to increased benefit in the mice. This idea is consistent with reports that have shown that strength and aerobic exercise can provide benefit to patients with LGMD2A/R1, 2I/R9, and $2 \mathrm{~L} / \mathrm{R} 12 .{ }^{6}$ The delivered hSGCA gene to the heart can compensate and protect cardiac tissue during increased activity. However, this potential additive effect of gene transfer therapy needs to be tested in greater depth.
Nevertheless, systemic gene transfer of hSGCA was shown to be safe and effective in all tissues, including the heart.

In previous clinical studies, we have shown that hSGCA packaged into the AAV1 capsid with expression driven by muscle-specific promoters resulted in transgene expression in skeletal muscle tissue after local delivery. ${ }^{8,18,30}$ In this study, we packaged hSGCA into rAAVrh74 to maximize delivery to target tissue (biodistribution). rAAVrh74 is a serotype isolated from lymph nodes of rhesus monkeys with high homology (93\%) to the AAV8 capsid that displays high affinity for skeletal and cardiac muscle tissue. ${ }^{9,15}$ The data in this study further support the ability of rAAVrh74 to achieve targeted de- 
livery to various skeletal muscle tissue. In addition, in the organs we tested, we demonstrated limited off-target effects that could be attributed to use of the muscle-specific promoter, tMCK, in driving hSGCA transgene expression in the appropriate tissues.

To improve efficiency of $\alpha$-SG protein expression, we packaged hSGCA into a self-complementary vector. Selfcomplementary AAV vectors contain an inverted repeat genome that promotes the formation of dsDNA, thus allowing replication and transcription to occur without the need for multiple vector genomes to promote these processes. $^{31,32}$ As such, use of self-complementary vectors eliminates the rate-limiting step to allow more rapid expression of the transgene. Indeed, the results from this study demonstrate expression 12 weeks after systemic administration at all doses tested.

Of interest, we recently have shown that intravascular gene transfer of scAAVrh74.tMCK.hSGCA in patients with LGMD2D/R3 was associated with increased $\alpha$-SG protein expression 180 days postgene transfer at doses of $1.0 \times 10^{12}$ and $3.0 \times 10^{12} .{ }^{14}$ It must be noted that a linear dose/response was not observed across all muscles and outcomes. Unlike traditional chemical and molecular therapies, the pharmacokinetics/pharmacodynamics of gene therapy is complex. It has been reported that the dose/ response of gene therapies in promoting expression is sigmoidal. ${ }^{33}$ Moreover, while it is hypothesized that a positive linear relationship between $\alpha$-SG protein expression and histopathological and functional outcomes should exist; there are limited data available to support a direct linear relationship across all measures. Nonetheless, our studies further support the ability of this construct to reduce viral load that would in turn potentially minimize toxicity, while maximizing biological and functional efficacy.

Supportive functional data in this study further demonstrate that the intravenous gene transfer of scAAVrh74.tMCK .hSGCA provides muscles with increased strength and resistance against contraction-induced damage in the TA and diaphragm muscles in all three vector-treated cohorts compared with vehicle-treated controls. Understanding the symptoms associated with LGMD2D/R3 is critical in reducing the severity of the disease, decreasing the incidence of death, and increasing the quality of life. ${ }^{5}$ After treatment, the diaphragms of mice generated muscle force comparable with levels observed in WT (normal) mice, revealing potential in keeping the diaphragm healthy and reducing the need for respiratory care and the prevention of respiratory distress.

In addition, treatment with scAAVrh74.tMCK.hSGCA resulted in a significant reduction in $\mathrm{CK}$, supporting the hypothesis that hSGCA gene transfer prevents muscle damage. Loss of ambulation is a devastating symptom of LGMD2D/R3 that must also be addressed with any potential treatment. Here we demonstrated that, after treat- ment with scAAVrh74.tMCK.hSGCA, mice were able to ambulate and rear onto hind limbs more frequently than vehicle-treated mice, providing support that the transfer of hSGCA increases ambulation, which has the potential to translate to patients with LGMD2D/R3.

Prominent histopathology, which includes centrally located nuclei, wide variability in fiber size, inflammation, necrosis, and fibrosis, is typically observed through muscle biopsies of patients with LGMD2D/R3. ${ }^{5}$ After hSGCA delivery, mice had a reduction in $\mathrm{CN}$, a more even distribution of myofiber size, and a reduction in collagen content, with muscles having an overall healthier appearance compared with vehicle-treated mice. It must be noted that the ability to reduce/reverse $\mathrm{CN}$ was muscleand dose-dependent. We observed that the $\mathrm{CN}$ reduction and fibrosis levels did not follow a dose-dependent pattern in the intermediate-dose cohort; however, this could be possibly attributed to baseline differences among the cohorts. Onset of progressive muscular dystrophy in $\mathrm{sgca}^{-/}$ mice occurs as early as 1 week of age. ${ }^{7}$ Nonetheless, the total reduction in histopathology and scar tissue was concomitantly associated with improvement in the overall normal function and physiology of the muscles in vectortreated mice.

Finally, safety studies conducted through qPCR, serum chemistry analysis, and histopathology lacked any signs of toxicity. Consistent with an earlier study by Wang et al. ${ }^{34}$ in which expression of luciferase driven by tMCK leakage in the liver was observed but was significantly less than the constitutive cytomegalovirus promoter and other promoters being tested, transgene expression regulated by the tMCK promoter was detected only in targeted tissues (all muscles) and was absent in other (nonmuscle) organs, except for the liver. Histopathology review of all tissues (including liver) by a certified veterinarian pathologist concluded that the systemic delivery of scAAVrh74.tMCK.hSGCA was not only safe in all tissues but also that gene transfer dramatically reduced the amount of dystrophic pathology found in skeletal muscles of vehicle-treated $\mathrm{sgca}^{-/-}$ mice. Chemistries performed on blood samples of vector-treated mice also support the lack of toxicity.

In sum, this dose-escalation study provides preclinical data to support that the lowest dose systemically tested here-that is, $1.0 \times 10^{12} \mathrm{vg}$ total $\left(5.0 \times 10^{13} \mathrm{vg} / \mathrm{kg}\right)$ - is sufficient to reduce the signs and symptoms associated with loss of $\alpha$-SG protein. At the lowest dose tested, functional improvement in all muscles, as demonstrated by increase in strength and locomotor behavior (ambulation and rearing), was observed in vector-treated mice. Safety studies show no signs of toxicity, even at the highest delivered dose of $6.0 \times 10^{12} \mathrm{vg}$ total $\left(2.0 \times 10^{14} \mathrm{vg} /\right.$ $\mathrm{kg}$ ), suggesting the potential ability to increase dose based on progression and the severity of the disease in a clinical setting of patients with LGMD2D/R3. 


\section{AUTHORS' CONTRIBUTIONS}

D.A.G. and L.R.K. designed the experiments. L.R.K. cloned and prepped the pAAV.tMCK.hSGCA plasmid. D.A.G. performed necropsies, tissue sectioning, immunofluorescence, histology experiments, and morphometric data analysis. E.R.P. performed Western blotting and quantitative PCR experiments. K.N.H. performed diaphragm and tibialis anterior physiology experiments and data analysis. D.A.G performed open-field cage activity experiments and data analysis. D.A.G. and L.R.K. wrote the article. All authors reviewed, edited, and approved the article.

\section{ACKNOWLEDGMENTS}

We thank Jerry R Mendell, MD, for providing advice on interpretation of findings and the Nationwide Children's Viral Vector Core for Vector Production. We would also like to thank Terri Shaffer, MLAS, RLATG, for performing intravenous tail vein injections. Finally, we would like to thank Dr. Kevin Campbell for his gift of the $\mathrm{sgca}^{-/-}$mice. Medical writing and editorial support were provided by Khampaseuth Thapa, $\mathrm{PhD}$ and Lucia Quintana-Gallardo, PhD, of Sarepta Therapeutics, Inc., and Purvi Kobawala Smith, MS, MPH, of Health \& Wellness Partners, LLC, Upper Saddle River, NJ, funded by Sarepta Therapeutics, Inc.

\section{AUTHOR DISCLOSURE}

D.A.G., E.R.P., R.A.P., E.L.P., and L.R.K. are employees of Sarepta Therapeutics, Inc. and may have stock options. K.N.H. has nothing to disclose.

\section{FUNDING INFORMATION}

This study was funded by Sarepta Therapeutics, Inc.

\section{SUPPLEMENTARY MATERIAL}

Supplementary Figure S1

Supplementary Table S1

\section{REFERENCES}

1. Liewluck T, Milone M. Untangling the complexity of limb-girdle muscular dystrophies. Muscle Nerve 2018;58:167-177.

2. Murphy AP, Straub V. The classification, natural history and treatment of the limb girdle muscular dystrophies. J Neuromuscul Dis 2015;2:S7-S19.

3. McNally EM. The Sarcoglycans. In: Madame Curie Bioscience Database [Internet]. Austin (TX): Landes Bioscience; 2000-2013. Accessed June 22, 2020. Available from: https://www.ncbi.nlm.nih .gov/books/NBK6317/

4. Taghizadeh E, Rezaee M, Barreto GE, et al. Prevalence, pathological mechanisms, and genetic basis of limb-girdle muscular dystrophies: a review. J Cell Physiol 2019;234:7874-7884.

5. Chu ML, Moran E. The limb-girdle muscular dystrophies: is treatment on the horizon? Neurotherapeutics 2018;15:849-862.

6. Vissing J. Limb girdle muscular dystrophies: classification, clinical spectrum and emerging therapies. Curr Opin Neurol 2016;29:635-641.

7. Duclos F, Straub V, Moore SA, et al. Progressive muscular dystrophy in alpha-sarcoglycan-deficient mice. J Cell Biol 1998;142:1461-1471.

8. Rodino-Klapac LR, Lee JS, Mulligan RC, et al. Lack of toxicity of alpha-sarcoglycan overexpression supports clinical gene transfer trial in LGMD2D. Neurology 2008;71:240-247.

9. Chicoine LG, Rodino-Klapac LR, Shao G, et al. Vascular delivery of rAAVrh74.MCK.GALGT2 to the gastrocnemius muscle of the rhesus macaque stimulates the expression of dystrophin and laminin alpha2 surrogates. Mol Ther 2014;22:713-724.
10. Potter RA, Griffin DA, Sondergaard PC, et al. Systemic delivery of dysferlin overlap vectors provides long-term gene expression and functional improvement for dysferlinopathy. Hum Gene Ther 2018;29:749-762.

11. Pozsgai ER, Griffin DA, Heller KN, et al. betaSarcoglycan gene transfer decreases fibrosis and restores force in LGMD2E mice. Gene Ther 2016; 23:57-66.

12. Pozsgai ER, Griffin DA, Heller KN, et al. Systemic AAV-mediated beta-sarcoglycan delivery targeting cardiac and skeletal muscle ameliorates histological and functional deficits in LGMD2E mice. Mol Ther 2017;25:855-869.

13. Mendell JR, Sahenk Z, Lehman K, et al. Assessment of systemic delivery of rAAVrh74.MHCK7.microdystrophin in children with Duchenne muscular dystrophy. JAMA Neurol 2020;77:1122-1131.

14. Mendell JR, Chicoine LG, Al-Zaidy SA, et al. Gene delivery for limb-girdle muscular dystrophy type $2 \mathrm{D}$ by isolated limb infusion. Hum Gene Ther 2019;30:794-801.

15. Chicoine LG, Montgomery CL, Bremer WG, et al. Plasmapheresis eliminates the negative impact of AAV antibodies on microdystrophin gene expression following vascular delivery. Mol Ther 2014; 22:338-347.

16. Rodino-Klapac LR, Janssen PM, Montgomery CL, et al. A translational approach for limb vascular delivery of the micro-dystrophin gene without high volume or high pressure for treatment of Duchenne muscular dystrophy. J Transl Med 2007;5:45.

17. Sondergaard PC, Griffin DA, Pozsgai ER, et al. $A A V$.dysferlin overlap vectors restore function in dysferlinopathy animal models. Ann Clin Transl Neurol 2015;2:256-270.

18. Mendell JR, Rodino-Klapac LR, Rosales XQ, et al. Sustained alpha-sarcoglycan gene expression after gene transfer in limb-girdle muscular dystrophy, type 2D. Ann Neurol 2010;68:629-638.

19. Schnepp BC, Jensen RL, Chen CL, et al. Characterization of adeno-associated virus genomes isolated from human tissues. J Virol 2005;79: 14793-14803.

20. Beastrom N, Lu H, Macke A, et al. mdx(cv) mice manifest more severe muscle dysfunction and diaphragm force deficits than do mdx Mice. Am J Pathol 2011;179:2464-2474.

21. Kobayashi YM, Rader EP, Crawford RW, et al. Sarcolemma-localized nNOS is required to maintain activity after mild exercise. Nature 2008;456: 511-515.

22. Voikar V, Polus $A$, Vasar $E$, et al. Long-term individual housing in C57BL/6J and DBA/2 mice: assessment of behavioral consequences. Genes Brain Behav 2005;4:240-252.

23. Hakim CH, Li D, Duan D. Monitoring murine skeletal muscle function for muscle gene therapy. Methods Mol Biol 2011;709:75-89.

24. Moorwood C, Liu M, Tian Z, et al. Isometric and eccentric force generation assessment of skeletal muscles isolated from murine models of muscular dystrophies. J Vis Exp 2031;71:e50036.

25. Rafael-Fortney JA, Chimanji NS, Schill KE, et al. Early treatment with lisinopril and spironolactone preserves cardiac and skeletal muscle in Duchenne muscular dystrophy mice. Circulation 2011;124:582-588. 
26. Clark KR, Liu X, McGrath JP, et al. Highly purified recombinant adeno-associated virus vectors are biologically active and free of detectable helper and wild-type viruses. Hum Gene Ther 1999;10: 1031-1039.

27. Rodino-Klapac LR, Montgomery CL, Bremer WG, et al. Persistent expression of FLAG-tagged micro dystrophin in nonhuman primates following intramuscular and vascular delivery. Mol Ther 2010; 18:109-117.

28. Walter MC, Dekomien G, Schlotter-Weigel B, et al. Respiratory insufficiency as a presenting symptom of LGMD2D in adulthood. Acta Myol 2004;23:1-5.

29. Straub V, Rafael JA, Chamberlain JS, et al. Animal models for muscular dystrophy show different patterns of sarcolemmal disruption. J Cell Biol 1997;139:375-385

30. Mendell JR, Rodino-Klapac LR, Rosales-Quintero $X$, et al. Limb-girdle muscular dystrophy type $2 \mathrm{D}$ gene therapy restores alpha-sarcoglycan and associated proteins. Ann Neurol 2009;66:290297.

31. McCarty DM, Fu H, Monahan PE, et al. Adenoassociated virus terminal repeat (TR) mutant generates self-complementary vectors to overcome the rate-limiting step to transduction in vivo. Gene Ther 2003;10:2112-2118.

32. McCarty DM, Monahan PE, Samulski RJ. Selfcomplementary recombinant adeno-associated virus (scAAV) vectors promote efficient transduc- tion independently of DNA synthesis. Gene Ther 2001:8:1248-1254.

33. Roychoudhury P, De Silva Feelixge HS, Pietz HL, et al. Pharmacodynamics of anti-HIV gene therapy using viral vectors and targeted endonucleases. J Antimicrob Chemother 2016;71:20892099.

34. Wang B, Li J, Fu FH, et al. Construction and analysis of compact muscle-specific promoters for AAV vectors. Gene Ther 2008;15:1489-1499.

Received for publication August 16, 2019; accepted after revision December 18, 2020.

Published online: December 21, 2020 